\title{
Inset-fed Multiband Square Patch Antenna on Flexible substrate for Fifth-Generation Wireless Communication
}

\author{
Sujata S. K. ${ }^{1^{*}} \&$ P. S. Aithal ${ }^{2}$ \\ ${ }^{1}$ Post-Doctoral Fellow, College of Engineering \& Technology, Srinivas University, \\ Mangalore, India \\ \& Assoc. Professor, Electronics \& Communication, Sharnbasav University, Kalaburagi, India \\ OrcidID: 0000-0001-5526-8141; E-mail: sujata.kamlapurkar@gmail.com \\ ${ }^{2}$ Faculty, College of Management \& Commerce, Srinivas University, Mangalore, India \\ OrcidID: 0000-0002-4691-8736; E-mail: psaithal@gmail.com
}

Subject Area: Wireless Communication.

Type of the Paper: Design based Research Analysis.

Type of Review: Peer Reviewed as per $|\mathrm{C}| \mathrm{O}|\mathrm{P}| \mathrm{E} \mid$ guidance.

Indexed In: OpenAIRE.

DOI: https://doi.org/10.5281/zenodo.5689664

Google Scholar Citation: IJAEML

\section{How to Cite this Paper:}

Sujata, S. K., \& Aithal, P. S., (2021). Inset-fed Multiband Square Patch Antenna on Flexible substrate for Fifth-Generation Wireless Communication. International Journal of Applied Engineering and Management Letters (IJAEML), 5(2), 106-118.

DOI: https://doi.org/10.5281/zenodo.5689664

International Journal of Applied Engineering and Management Letters (IJAEML) A Refereed International Journal of Srinivas University, India.

Crossref DOI : https://doi.org/10.47992/IJAEML.2581.7000.0107

(C) With Authors.

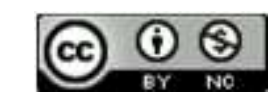

This work is licensed under a Creative Commons Attribution-Non-Commercial 4.0 International License subject to proper citation to the publication source of the work.

Disclaimer: The scholarly papers as reviewed and published by the Srinivas Publications (S.P.), India are the views and opinions of their respective authors and are not the views or opinions of the S.P. The S.P. disclaims of any harm or loss caused due to the published content to any party. 


\title{
Inset-fed Multiband Square Patch Antenna on Flexible substrate for Fifth-Generation Wireless Communication
}

\author{
Sujata S. K..$^{*} \&$ P. S. Aithal ${ }^{2}$ \\ ${ }^{1}$ Post-Doctoral Fellow, College of Engineering \& Technology, Srinivas University, \\ Mangalore, India \\ \& Assoc. Professor, Electronics \& Communication, Sharnbasav University, Kalaburagi, India \\ OrcidID: 0000-0001-5526-8141; E-mail: sujata.kamlapurkar@gmail.com \\ ${ }^{2}$ Faculty, College of Management \& Commerce, Srinivas University, Mangalore, India \\ OrcidID: 0000-0002-4691-8736; E-mail: psaithal@gmail.com
}

\begin{abstract}
Purpose: Over a decade, the antenna has sparked considerable interest in the $5 G$ frequency band in the wireless domain (covering industrial applications, home automation and mobile communication) because of its numerous advantages like compact, conformal to surfaces, easily integrated with the devices, etc. In general, an Antenna can be defined as a conductor which is exposed to space operable for a specific application. The purpose of the study is to design the Slotted patch antenna for $5 G$ applications on a flexible dielectric substrate material which makes the antenna compact in its design aspect.
\end{abstract}

Design/Methodology/Approach: Initially, the antenna design is carried out using the theoretical framework based on the available equations. The microwave studio software Computer Simulation Technology (CST) is used to create and model the different antennas.

Findings/Result: Based on the simulated models, the slotted patch antenna design 5 has 2 bands namely: $3.25 \mathrm{GHz}$, the return loss is $-17.47 \mathrm{~dB}$, and $5.89 \mathrm{GHz}$, the return loss is $-21.37 \mathrm{~dB}$. Whereas design 6 has 4 resonant bands measured at $2.04 \mathrm{GHz}$, the return loss $(R L)$ is -11.68 $\mathrm{dB}$, at $5.80 \mathrm{GHz}$, the $R \mathrm{~L}$ is $-22.36 \mathrm{~dB}$, at $7.14 \mathrm{GHz}$, the $R L$ is $-28.71 \mathrm{~dB}$ and at $8.83 \mathrm{GHz}$, the $R L$ is $-13.36 \mathrm{~dB}$. The maximum bandwidth achieved for slotted patch antenna design 5 is $5 \%$ and the maximum bandwidth achieved for slotted patch antenna design 6 is $8 \%$. Whereas the design of Multi slotted patch antenna flexible substrate design 7 and design 8 has the maximum achieved bandwidth of $10 \%$.

Originality/Value: The design of slotted patch and multi slotted patch antenna using inset feed method on a flexible substrate for $5 G$ frequency band.

Paper Type: Design based Research Analysis.

Keywords: Multiband antenna, $5^{\text {th }}$ generation wireless communication, Inset-feed method, Electromagnetic wave propagation, Return loss of antenna, Slotted Patch Antenna, Flexible substrate.

\section{INTRODUCTION :}

The microstrip antenna in 5G frequency band of wireless arena (industrial applications, home automation and mobile communication) has been intensively used because of its numerous advantages like compact, conformal to surfaces, easily integrated with the devices etc. In general, Antenna can be defined as a conductor which exposed to space operable for specific application. Because of its ease of analysis and construction, less production costs and appealing radiation properties, the patch antenna is one of the most commonly utilized solution for several possible antenna configurations. It also suffers few drawbacks such as low gain, limited bandwidth, surface wave losses and a large beam width.

\section{RELATED WORKS :}

N. Mohamed Sobidha Banu, et al, (2015), focussed the inset feed approach, the square microstrip patch antenna with a frequency of $2.6 \mathrm{GHz}$ that is suited for S-band applications is designed. The researcher concentrated on the magnitude and antenna performance. The antenna is intended for S-band communication at $2.6 \mathrm{GHz}$, with a radiation pattern that covers a large angle of beam and a strong gain. The recommended antenna's resonance frequency is good, as is the return loss, VSWR [1]. Zain Ul 
Abedin and Zahid Ullah (2017) investigated the high-bandwidth, high-gain microstrip patch antenna for UWB and other wireless communications. The main aim is to obtain a large bandwidth, by using FR4 dielectric material of $1.6 \mathrm{~mm}$ thick having $\varepsilon r$ of 4.4. As the consequence, the antenna's bandwidth ranged from $2.33 \mathrm{GHz}$ to $12.4 \mathrm{GHz}$, with $90 \%$ efficiency in radiation for the UWB region. The antenna's coverage range is from $3.1 \mathrm{GHz}$ to $10.6 \mathrm{GHz}$, which is a wide band range. It also encompasses the scope of a local area network as well as the scope of satellite communication for both uplink and downlink [2]. In the paper, P Saleem Akram et al, (2018), the microstrip line feed with slotted patch was carried out. The design was done using HFSS software. The placement of a slot at the ground enhances the bandwidth. In comparison to previous models, the design consists of 10 iterations at the three edges of the UWB with high gain. It intends to be in the Ultra-wide band range $(3.1 \mathrm{GHz}-10.6 \mathrm{GHz})$ for WiMAX, WLAN 802.11, and LTE 42/43 [3]. Nikita M. Tarpara et.al., (2018), designed the slotted microstrip patch for $5 \mathrm{G}$ application. By loading some slots within the radiating patch, the lower resonance was seen in this study because of surface-current paths meandering on patch, consequently the bandwidth increases. This frequency varies slowly for different slot width in comparison with antenna without slot. It helps the bandwidth as well as the gain to increase in accordance with the slot width [4]. 5G mmWave patch was investigated by M.D. Madhan and D. Subitha (2019). Due to several microstrip antenna disadvantages, the researchers of this work have considered aspects on how to enhance them. By using Detected Ground Structure (DGS) technique, the efficiency, bandwidth, the gain are enhanced [5]. Muhammad Afiq Abdul Aziz et al designed a microstrip patch antenna for 5G at several frequencies over $20 \mathrm{GHz}$ (2019). This antenna was designed on RT duriod Substrate whose $\mathcal{E} r$ is 2.2. The designed antenna has a fractional bandwidth, gain, and directivity of more than 10.2 percent, $2.159 \mathrm{~dB}$, and 2.562dB, respectively [6]. Naser Ojaroudi Parchin, et al, (2020) proposed a loss-profile dual-band MIMO patch antenna array for 4G/LTE and 5G wireless communication with better isolation. The feeding mechanism consists of two coaxial-fed patch antennas with U-shaped slots that provide dualband operation in the $2.6 / 3.6 \mathrm{GHz} 4 \mathrm{G} / 5 \mathrm{G}$ bands. As the consequence the isolation is enhanced by about $13 \mathrm{~dB}$ and $10 \mathrm{~dB}$ at the operation frequencies with the parasitic structure [7]. Rezaul Azim et al (2020) shows a multi-slotted patch for long term evolution (LTE) and 5G. It uses three slots to enhance the capacitive effect. The antenna gives omnidirectional radiation pattern, great gain and efficiency, to give the suggested antenna a chance to be used for WiFi, WLAN, LTE, 5G, etc [8]. The work reported by Kalsouabe Zoukalne, et al, (2020) about the design of microstrip patch antenna array for 5G which resonate at 3.6GHz. It was designed on Rogers RO4350 (tm) substrate, having a thickness of $3.54 \mathrm{~mm}$ and $\varepsilon r=3.66$, it contains three slots, in which, two are put in the radiating elements and one on the power line. The proposed antenna provides a gain of $9 \mathrm{dBi}$ and a bandwidth of $200 \mathrm{MHz}$ [9]. M. M. Hasan Mahfuz et al, (2021), demonstrate the use of a ring shape resonator (RSR) on the ground to create a UWB patch antenna with a $5 \mathrm{G}$ lower band notch. The VSWR, return loss, 2-D radiation pattern, surface current, radiation efficiency, and gain all show that it is an excellent 5G solution [10]. Mohammad Alibakhshikenari and colleagues (2021) investigated a wide-band sub-6 GHz self-grounding Bow-tie antenna with a novel feeding method for $5 \mathrm{G}$ communication systems. This antenna covers 3.35 to 4.4 GHz. It is composed of two petal shaped metal structure. Electromagnetic coupling is used as the method of feeding the petals, with the principle of an open circuit [11] as a result of all of these designs. The current study presents the design of slotted and multi slotted patch design on flexible dielectric substrate material designed for $6 \mathrm{GHz}$ suitable for $5 \mathrm{G}$ applications.

\section{OBJECTIVES :}

The paper deals with the antenna design on flexible dielectric substrate and extending with the slotted patch antenna designs based on the available methods as noted in literature review within the design simulation constraints. The adopted method in the designs will be studied to meet the below objectives:

(1) To theoretically design the patch antenna that can be validated with the simulated designs for $6 \mathrm{GHz}$ frequency.

(2) To design the slotted and multi slotted patch antenna with inset fed excitation method.

(3) To develop computer simulated antenna design suitable for 5G wireless applications.

(4) To determine return loss, bandwidth and radiation characteristics of the patch antennas.

(5) To perform simulation iterations of the designed antenna on the CST microwave studio and to obtain the desired resonance. 


\section{METHODOLOGY :}

This paper consists of patch antenna designed using a theoretical framework based on the available equations [12] that are available. The antennas are fed with Inset feeding method and the different antennas are designed and tested using the Computer Simulation Technology microwave studio software.

\section{DESIGN AND RESULTS :}

The various designs are considered in this present study and initially it starts with the simple flexible patch antenna, followed by Slotted Patch Antenna-Design 5 and 6 and Multi Slotted Patch AntennaDesign 7 and 8.

\subsection{Design and Results of Simple Flexible Patch Antenna:}

Figure 1 shows the design of a slotted flexible patch antenna constructed on a Kepton polyimide substrate material having dielectric permittivity $(\mathcal{E r})$ of 3.4 , the equations used to calculate the dimensions as given in [12] and the dimensions of simple patch antenna are, Patch length $(L)$ is 1.66 $\mathrm{cm}$, Patch width $(W)$ is $1.66 \mathrm{~cm}$, both Ground length $(S l)$ and Ground width $(S w)$ is $1.68 \mathrm{~cm}$. The flexible substrate thickness $(H S)$ is $0.0125 \mathrm{~cm}$ and its copper thickness $(H P)$ is $0.0035 \mathrm{~cm}$. The flexible patch is fed with inset-fed excitation method and its dimensions are; width of feed $(w f)$ is $0.1 \mathrm{~cm}$ and the inset length $(F i)$ is $0.44 \mathrm{~cm}$. The calculated dimensions are the functions of the operating wavelength as per the chosen design frequency $6 \mathrm{GHz}$ which is acceptable for $5 \mathrm{G}$ wireless band applications. The design of simple square patch antenna selected is designed at $6 \mathrm{GHz}$ frequency and is as shown in figure 1. EMCST (SV) computer software is used for antenna design. The simulated antenna has an RL of -11.52dB and operated at $5.35 \mathrm{GHz}$. The simulated resonance is quite close in agreement with chosen design frequency and hence validates the theoretical design.

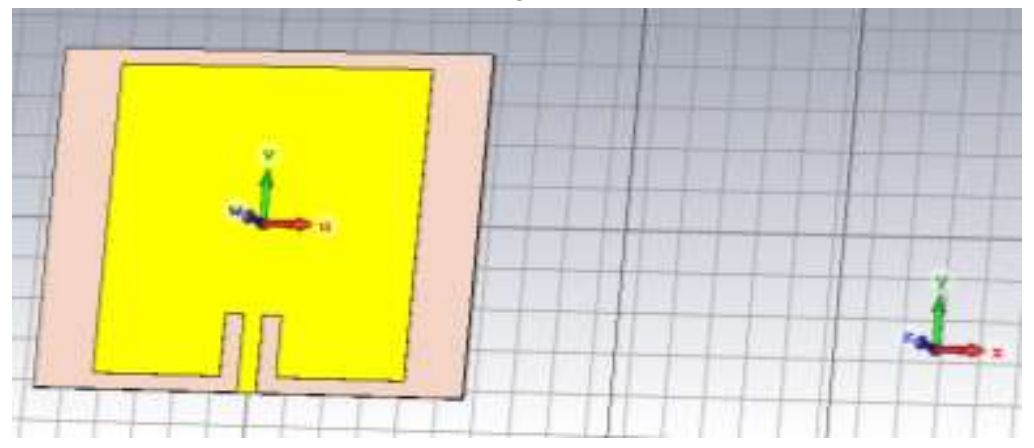

Fig. 1: Simple patch antenna (on flexible substrate)

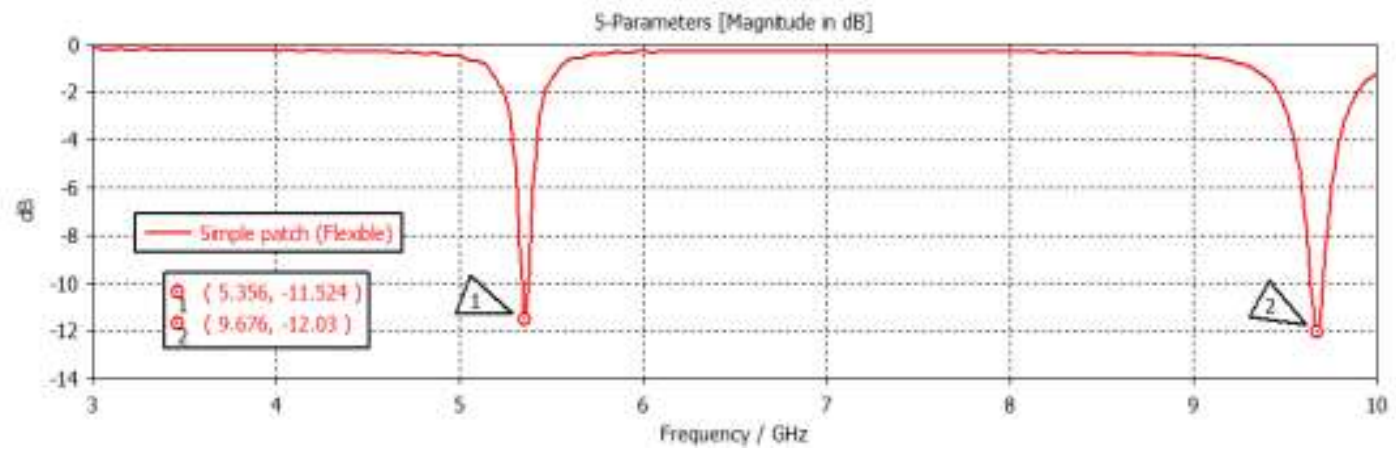

Fig. 2: Graph of $S \_11$ for Simple square patch antenna (on flexible substrate)

As per the above figure 2, it is also observed that, the antenna is resonating at two different bands for simple square patch antenna with RL of $-11.52 \mathrm{~dB}$ at $5.35 \mathrm{GHz}$ and a RL of $-12.03 \mathrm{~dB}$ at $9.67 \mathrm{GHz}$, which is acceptable for a normal operation in the frequency band. Hence, this type of single antenna (Simple patch antenna (on flexible substrate)) can be used for both transmission and reception for application in $5 \mathrm{G}$ band. The maximum bandwidth achieved for this is $3 \%$. The surface current distribution on simple flexible square patch antenna is shown in Figure 3. It is clearly seen that the radiation happens along the width side of the patch. The maximum current concentration is from feed 
portion to the edges of the patch.

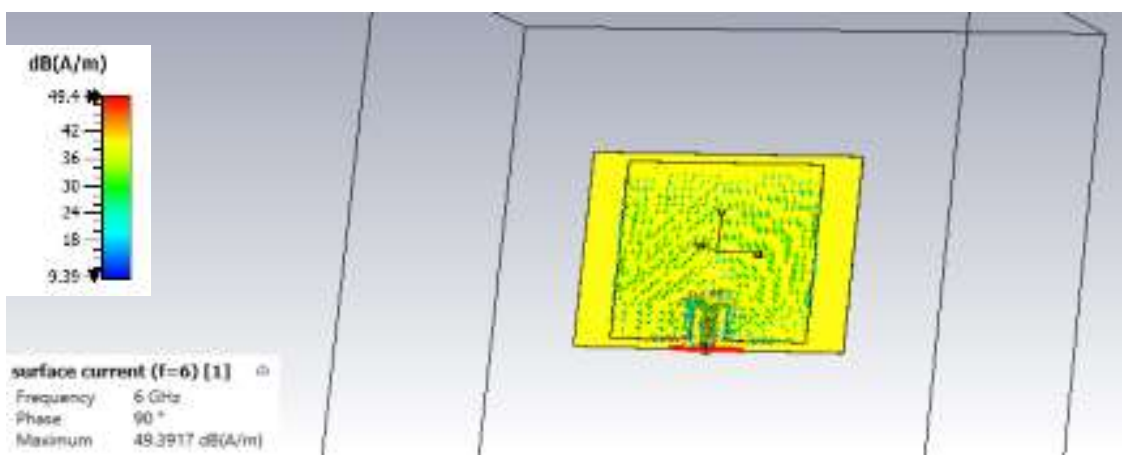

Fig. 3: Current distribution for Simple patch antenna (Flexible substrate)

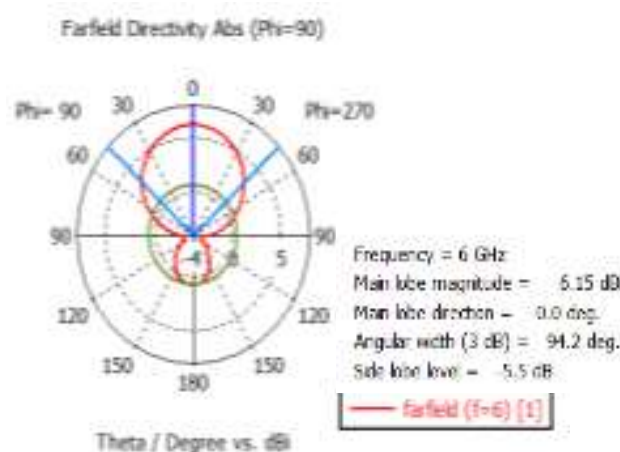

(a)

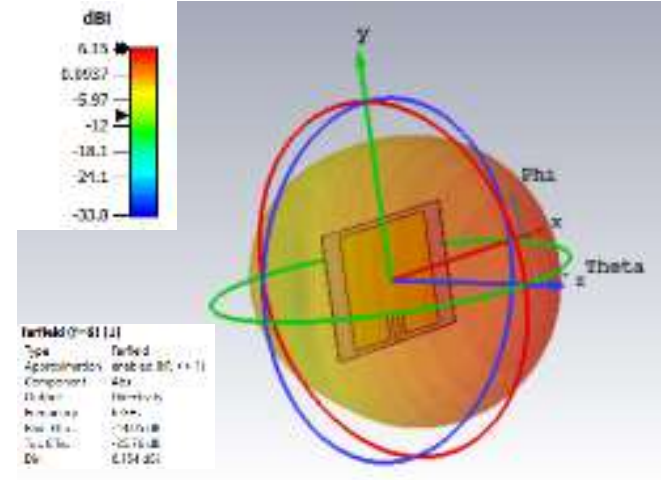

(b)

Fig. 4: a) 2D and b) 3D patterns for simple square flexible patch antenna

Figure 4 shows the 2D and 3D radiation patterns working at $6 \mathrm{GHz}$, having a major lobe magnitude of roughly $6.15 \mathrm{~dB}$. The main lobe direction is at $0^{\circ}$, the antenna radiates up to an angular width of 94.3 degrees, and with minor side lobes of $-5.5 \mathrm{~dB}$. From the figure it is clear that, this antenna radiates in broadsided nature.

\subsection{Design and Results of Slotted Patch Antenna-Design 5 and 6:}

Figure 5.a and 5.b represent the design of slotted-patch antenna with different type of slots shapes. The both design 5(a) and 5(b) have the same dimensions as that of simple patch antenna except the fact that they have some slots with different shapes and sizes. These dimensions are functions of wavelength factor like half wavelength and fractional wavelength with respect to the actual considered wavelength.

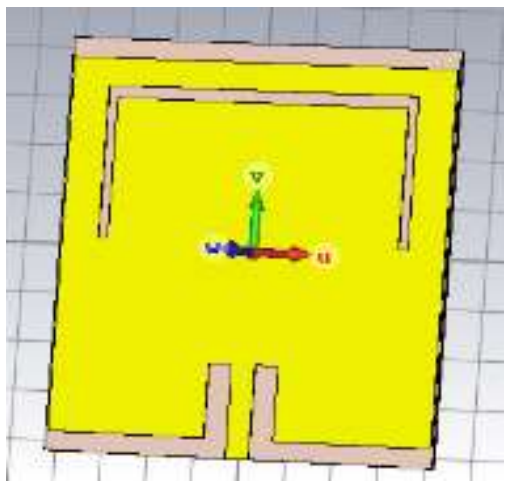

(a)

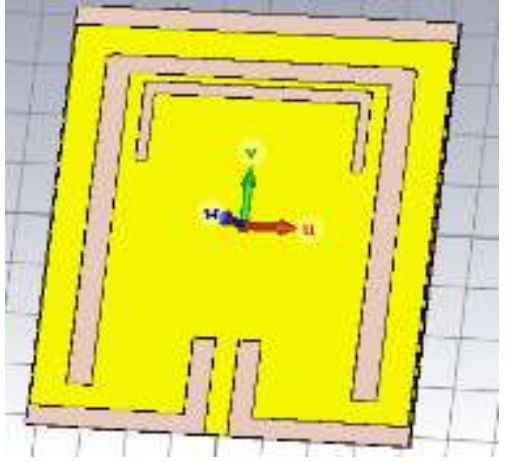

(b)

Fig. 5: a) Slotted Patch Design 5, b) Slotted Patch Design 6 (on flexible Kepton polyimide substrate)

The dimensions and position of the slots for Slotted Patch Design 5 on flexible Kepton polyimide substrate are given as: 
For First slot:

Slot Width

$-\mathrm{W} / 2+0.2$

$\mathrm{W} / 2-0.35$

Slot Length

$-\mathrm{L} / 2-0.9$

$\mathrm{L} / 2-0.19$

Slot Thickness

HS

$\mathrm{HS}+\mathrm{HP}$

Second slot:

Slot Width

-wf/2-0.62

$\mathrm{wf} / 2+0.62$

Slot Length

$\mathrm{wf} / 2+0.65$

$\mathrm{wf} / 2+0.0 .6$

Slot Thickness

HS

$\mathrm{HS}+\mathrm{HP}$

The dimensions and position of the slots for Slotted Patch Design 6 on Flexible Kepton polyimide substrate are given as below:

First slot:

Slot Width

$-\mathrm{W} / 2+0.2$

$\mathrm{W} / 2-0.35$

Slot Length

$-\mathrm{L} / 2-0.9$

$\mathrm{L} / 2-0.19$

Slot Thickness

HS

$\mathrm{HS}+\mathrm{HP}$

Second slot:

Slot Width

Slot Length

-wf/2-0.62

$\mathrm{wf} / 2+0.62$

wf $/ 2+0.65$

$\mathrm{wf} / 2+0.6$

Slot Thickness

HS

$\mathrm{HS}+\mathrm{HP}$

Third Slot:

Slot Width

Slot Length

Slot Thickness

$-w f / 2-0.61$
$-w f / 2+0.63$
HS

$-w f / 2+0.15$

L/2-1.5

$\mathrm{HS}$ $w f / 2+0.61$

$\mathrm{wf} / 2+0.6$

$\mathrm{HS}+\mathrm{HP}$

Fourth Slot:

Slot Width

Slot Length

Slot Thickness

wf/2-0.14

L/2-0.19

$\mathrm{HS}+\mathrm{HP}$

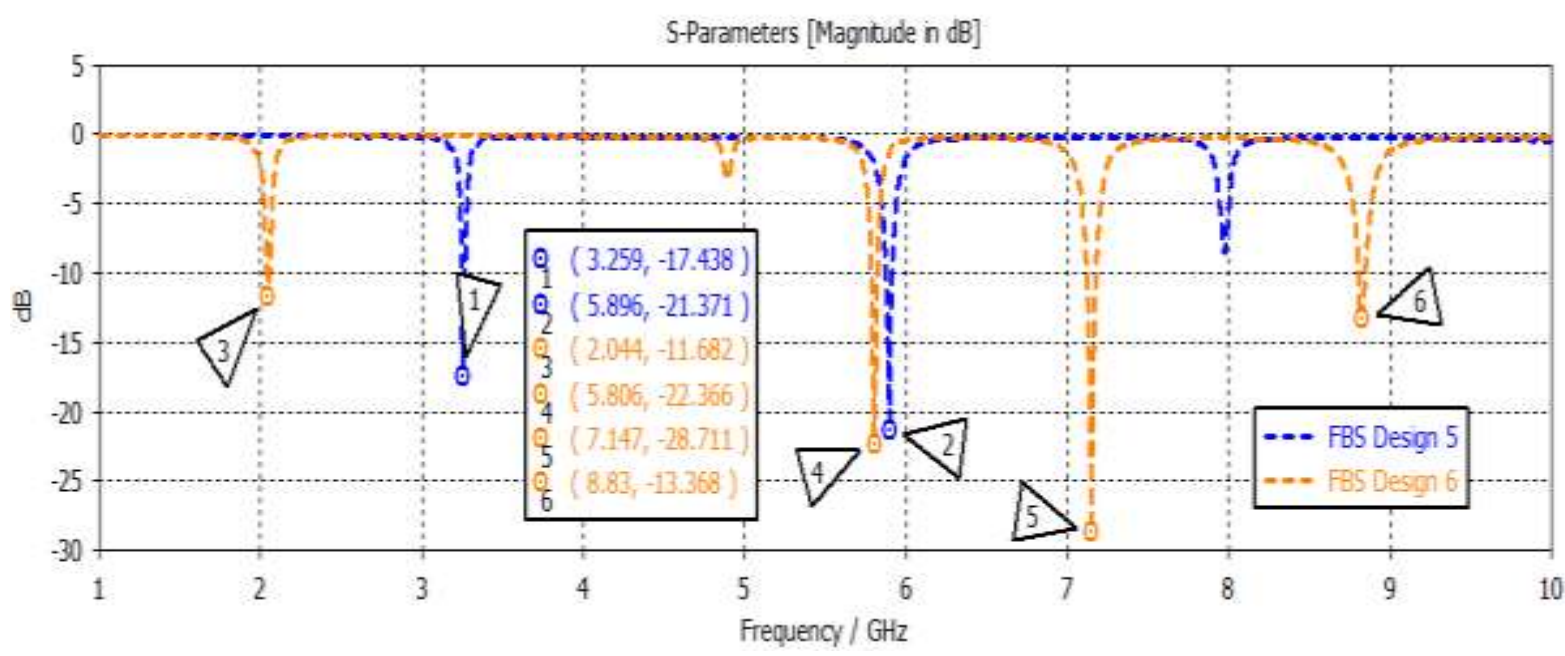

Fig. 6: Graph of S11 Slotted Patch Antenna for Design 5 and Design 6 on flexible Kepton polyimide substrate

Figure 6 represents the graph of S-parameter (RL or $S_{11}$ ) of Slotted Patch Antenna: Design 5 and Design 6 on Flexible Kepton polyimide substrate. Both the designs have obtained a good return loss, comparatively. The Slotted Patch Antenna for design 6 has better $S_{11}$ output characteristic in the form of multiband nature because it represents more bands as compared to the design 5. The maximum bandwidth achieved for Slotted Patch Antenna- Design 5 is 5\% and the maximum bandwidth achieved 
for Slotted Patch Antenna- Design 6 is $8 \%$. The design 5 has 2 bands namely: the first resonance is at $3.25 \mathrm{GHz}$ with the RL of $-17.47 \mathrm{~dB}$, and the second resonance is at $5.89 \mathrm{GHz}$ with the RL of $-21.37 \mathrm{~dB}$. Whereas, the design 6 has 4 resonant bands measured at $2.04 \mathrm{GHz}$, the RL $-11.68 \mathrm{~dB}$, at $5.80 \mathrm{GHz}$, the RL of $-22.36 \mathrm{~dB}$, at $7.14 \mathrm{GHz}$, the RL of $-28.71 \mathrm{~dB}$ and at $8.83 \mathrm{GHz}$, the RL of $-13.36 \mathrm{~dB}$. The obtained bandwidths are enhanced due to the addition of single and double inverted $\mathrm{C}$ type slots in both the designs due to which the current elongation on the surface of the patch increases which make the antenna resonate at multiband frequencies as shown in Figure 7.
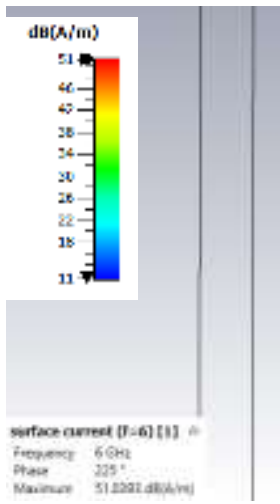

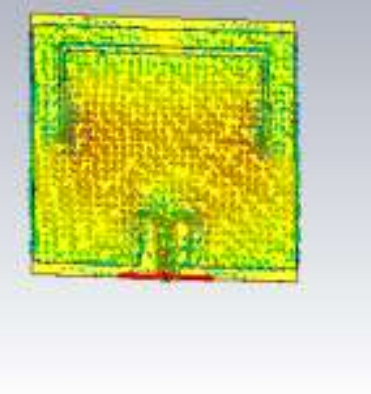

(a)

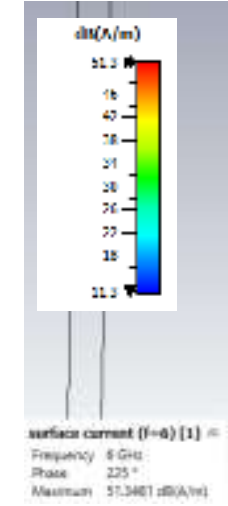

(b)

Fig. 7: a) Current distribution for Slotted Patch Design 5, b) Current distribution for Slotted Patch Design 6 (on Flexible Kepton polyimide substrate)

Figure 7 (a) and 7 (b) represent the surface current distribution on the patch, designed on flexible substrate. Both figures show the currents are disturbed accordingly and distributed on all patch area and on slot. The current becomes high in the edges of the slots, which creates multi resonance.

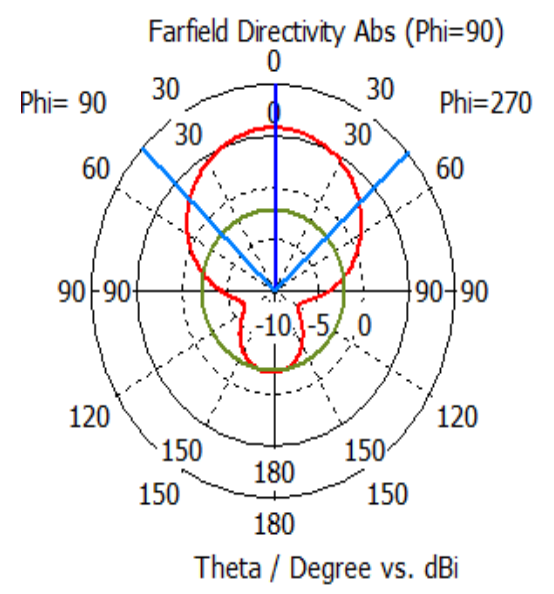

\author{
Frequency $=6 \mathrm{GHz}$ \\ Main lobe magnitude $=5.74 \mathrm{dBi}$ \\ Main lobe direction $=1.0 \mathrm{deg}$. \\ Angular width $(3 \mathrm{~dB})=94.0 \mathrm{deg}$. \\ Side lobe level $=-7.9 \mathrm{~dB}$
}

(a) 


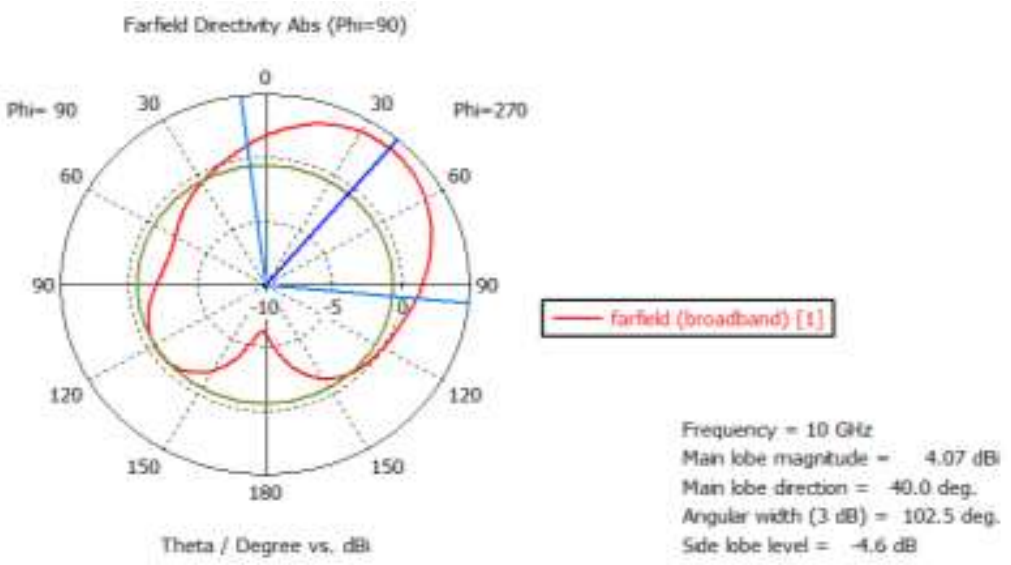

(b)

Fig. 8: a) 2D Radiation pattern for Slotted Patch Antenna. a) Design 5 and b) for Design 6 (flexible substrate)

Figure 8(a) and 8(b) represent the 2D polar radiation pattern for Slotted Patch Antenna design 5 and design 6 fabricated on Kepton polyimide flexible substrate. For the design 5, at resonance $6 \mathrm{GHz}$, the main lobe direction is of 1.0 degrees, the main lobe magnitude is of $5.74 \mathrm{~dB}$, the angular width is of 94.0 degrees and a side lobe level of $-7.9 \mathrm{~dB}$, whereas, in the design 6 , operating at the same operating frequency, the main lobe magnitude is $4.07 \mathrm{~dB}$ at main lobe direction of 40.0 degrees.

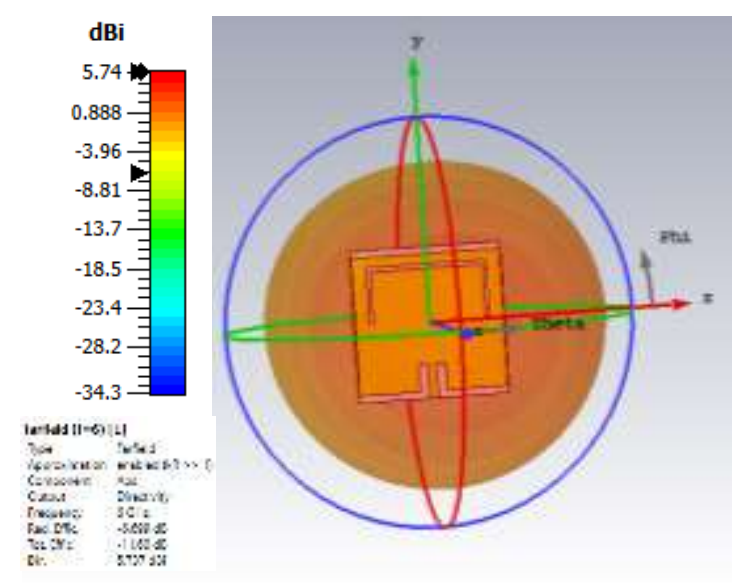

(a)

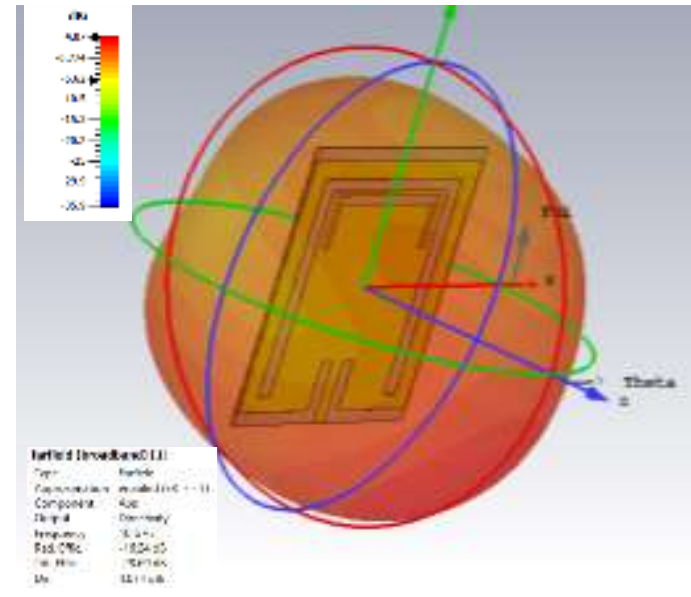

(b)

Fig. 9: a) 3D patterns. a) slotted patch design 5 and b) slotted patch design 6 (flexible substrate)

Figure 9(a) and 9(b) represent the 3D Radiation pattern for both design 5 and design 6 for Slotted Patch Antenna on Kepton polyimide flexible substrate. The arrows indicate the direction in which the power is radiated. As it is clearly visible, the radiations are broadsided in nature.

\subsection{Design and Results of Multi Slotted Patch Antenna-Design 5 and 6:}

The next type of slotted antenna design involves the etching of plus shape slot design with wide rectangular slot and the design of without plus shape slot with wider rectangular slots. The figure 10 . (a) and 10. (b) represent the design of multi slotted patch antenna with different slots and shapes. The design as shown in figure 10. (a) and 10. (b) have the same dimensions as that of simple patch antenna except the fact that they have some more slots with different shapes and sizes as a function of operating wavelength. 


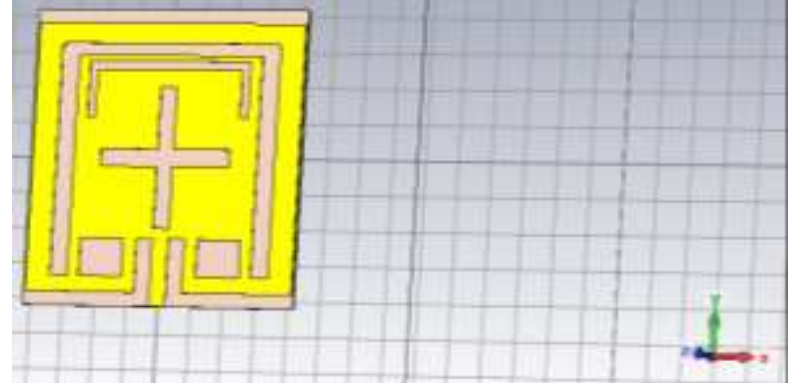

(a)

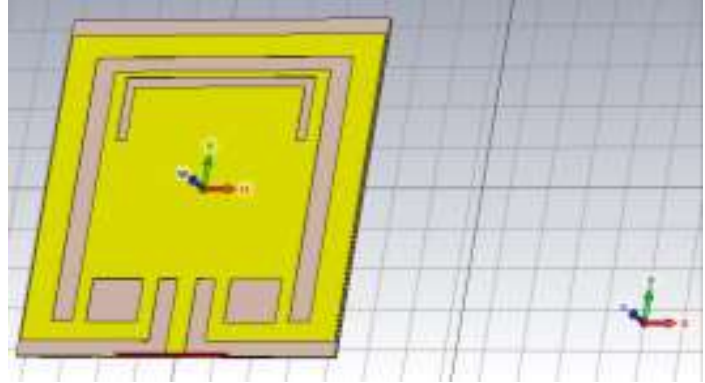

(b)

Fig. 10: a) Multi Slotted Patch Design 7, b) Multi Slotted Patch Design 8 (on Flexible kepton polyimide substrate)

The dimensions and position of the slots for Multi Slotted Patch design 7 on flexible Kepton polyimide substrate are given as:

First slot:

Slot Width

Slot Length

Slot thickness

W/2-0.35

L/2-0.19

$\mathrm{HS}+\mathrm{HP}$

Second slot:

Slot Width

Slot Length

-wf/2-0.62

$\mathrm{wf} / 2+0.65$

Slot thickness

HS

Third slot:

Slot Width

Slot Length

$$
\begin{gathered}
-w f / 2-0.61 \\
w f / 2+0.63
\end{gathered}
$$

HS

Fourth slot:

Slot Width

Slot Length

$-\mathrm{W} / 2+0.15$

L/2-1.5

HS

Slot thickness

Fifth slot:

Slot Width

Slot Length

-wf/2-0.45

$-\mathrm{sl} / 2+\mathrm{dl}+0.09$

HS

Sixth slot:

Slot Width

Slot Length

$$
\begin{aligned}
& -w f / 2-0.35 \\
& -w f / 2+0.03 \\
& \text { HS }
\end{aligned}
$$

W/2-1.4

L/2-0.19

$\mathrm{sl} / 2-\mathrm{dl}-\mathrm{L}+\mathrm{fi}$

$\mathrm{HS}+\mathrm{HP}$
$\mathrm{wf} / 2+0.62$
$\mathrm{wf} / 2+0.6$
$\mathrm{HS}+\mathrm{HP}$

$$
\begin{aligned}
& \text { wf/2+0.61 } \\
& \text { wf/2+0.6 } \\
& \text { HS+HP }
\end{aligned}
$$

\section{HS+HP}

$\mathrm{wf} / 2+0.35$

wf/2-0.03

$\mathrm{HS}+\mathrm{HP}$

The dimensions and position of the slots for Multi Slotted Patch design 8 on Flexible Kepton polyimide substrate are given as below:

First slot:

Slot Width

$$
\begin{aligned}
& -\mathrm{W} / 2+0.2 \\
& -\mathrm{L} / 2-0.9
\end{aligned}
$$

$\mathrm{W} / 2-0.25$

Slot Length

$\mathrm{L} / 2-0.19$

Slot thickness

HS

$\mathrm{HS}+\mathrm{HP}$

Second slot:

Slot Width

$-w f / 2-0.62$

$\mathrm{wf} / 2+0.62$ 


$\begin{array}{lll}\text { Slot Length } & \text { wf } / 2+0.65 & \text { wf } / 2+0.6 \\ \text { Slot thickness } & \text { HS } & \text { HS }+ \text { HP }\end{array}$

Third Slot:

Slot Width

Slot Length

$$
\begin{aligned}
& -w f / 2-0.61 \\
& -w f / 2+0.63 \\
& \text { HS }
\end{aligned}
$$

Fourth Slot:

Slot Width

Slot Length

Slot thickness

$-w f / 2+0.15$
L/2-1.5
HS

$\mathrm{wf} / 2+0.61$

$\mathrm{wf} / 2+0.6$

$\mathrm{HS}+\mathrm{HP}$

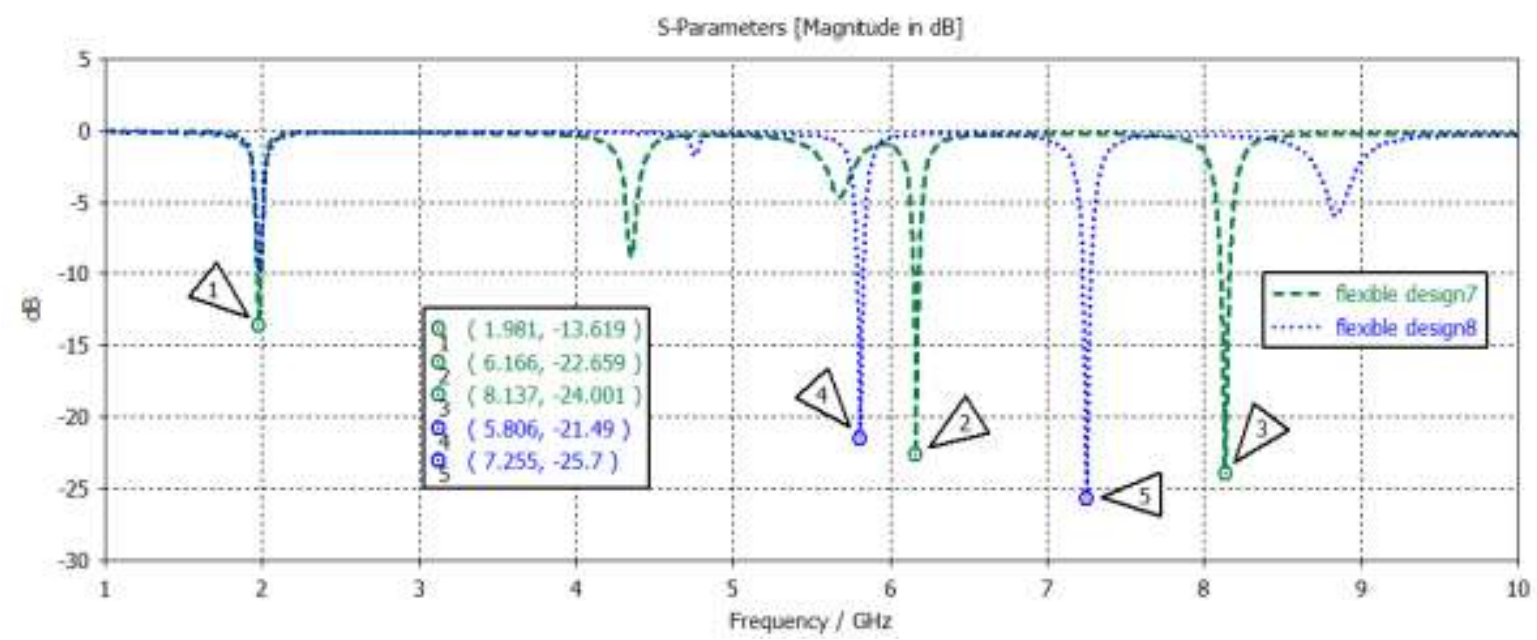

Fig. 11: Graph of S11 for both design 7 and 8 (Multi slotted antenna for flexible substrate)

Figure 11 represents the graph of S-parameter $\left(S_{11}\right)$ of Multi Slotted Patch Antenna for design 7 and design 7 on same flexible Kepton polyimide material. Both the designs have obtained a better return loss, comparatively. The Multi Slotted Patch Antenna for design 7 has better $S_{11}$ output characteristic and is in the form of triple band nature because it represents more bands as compared to the design 8 . The maximum bandwidth achieved for Multi Slotted Patch Antenna- design 7 is 9\% and the maximum bandwidth achieved for Multi Slotted Patch Antenna- design 8 is 10\%. The design 7 comprises three main bands: the first is at $1.98 \mathrm{GHz}$ and has a RL of $-13.61 \mathrm{~dB}$, the second resonance is attained at 6.169 $\mathrm{GHz}$ and has a RL of $-22.1 \mathrm{~dB}$, and the third resonance is at $8.13 \mathrm{GHz}$ and has a RL of $-24.0 \mathrm{~dB}$. The Multi Slotted Patch Antenna for design 8 contains two simulated resonant bands, with RL of $-21.4 \mathrm{~dB}$ at $5.8 \mathrm{GHz}$ and $\mathrm{RL}$ of $-25.7 \mathrm{~dB}$ at $7.2 \mathrm{GHz}$. The achieved bandwidths and minimum return loss are enhanced due to the addition of wider rectangular slot with plus shape slots in the center of patch slots in both the designs due to which the current elongation on the surface patch increases making it to have triple band characteristics as shown in Figure 11.

Figure 12 (a) and 12 (b) represent the surface current distribution on the patch, designed on Multi Slotted Patch flexible substrate. Both figures show the currents are disturbed accordingly and distributed on all patch area and on slot the current becomes high in the edges of the slots, which creates dual and triple resonance for $5 \mathrm{G}$ wireless communication applications.

Figure 13 (a) and 13 (b) represent the 2D radiation polar plot for multi-slotted flexible substrate. For the design 7, at resonance $6 \mathrm{GHz}$, the main lobe direction is of 5.0 degrees, the main lobe magnitude is of $5.84 \mathrm{~dB}$, the angular width is of 80.3 degrees and a minor side lobe level of $-4.8 \mathrm{~dB}$, whereas, in the design 8 , operating at the same operating frequency, the main lobe magnitude is $5.5 \mathrm{~dB}$ at main lobe direction of 179 degrees, having angular width of 70.9 degrees and minor side lobe level of 8.3dB.Figures 14(a) and 14(b) illustrate the 3D radiation patterns for Multi Slotted Patch Antennas on flexible dielectric substrates with minimal side lobe levels for designs 7 and 8 . The arrows in the patterns indicate the direction in which the power is radiated. As it is clearly visible, the radiations are broadsided in nature with less cross polar levels. 


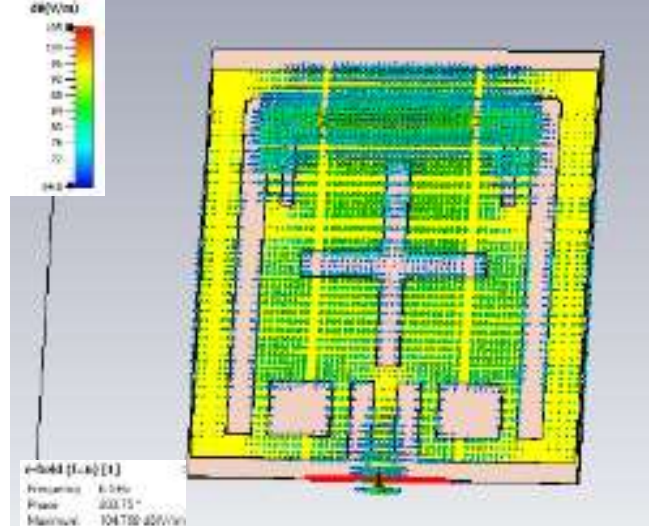

(a)

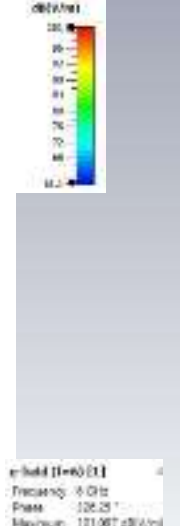

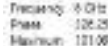

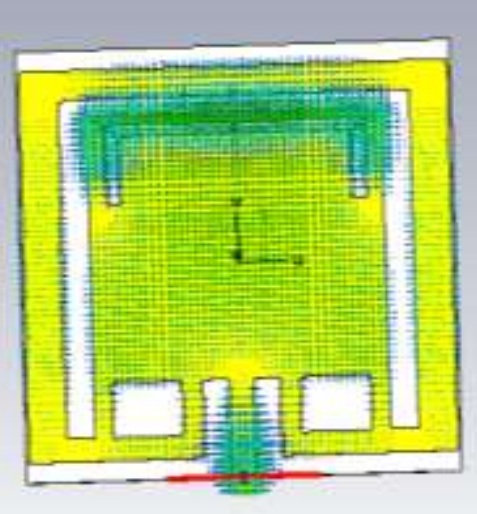

(b)

Fig. 12: a) Current distribution for Multi Slotted Patch Design 7, b) Current distribution for Multi Slotted Patch Design 8 (on Flexible kepton polyimide substrate)

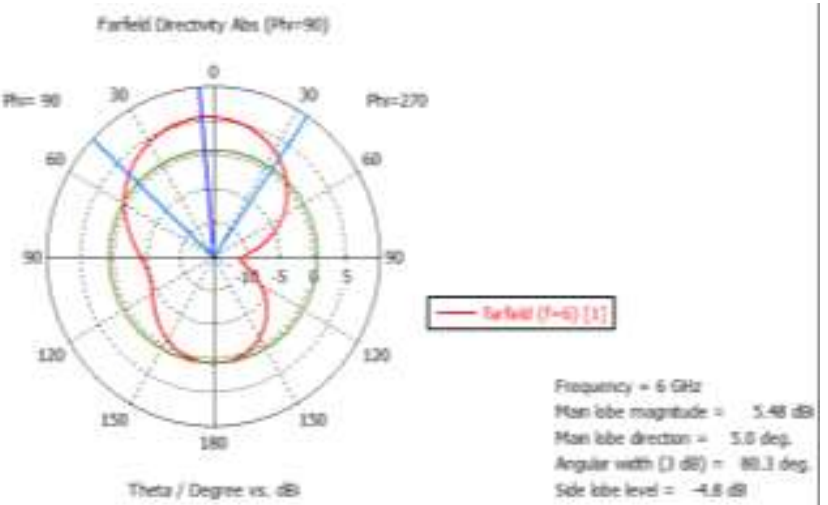

(a)

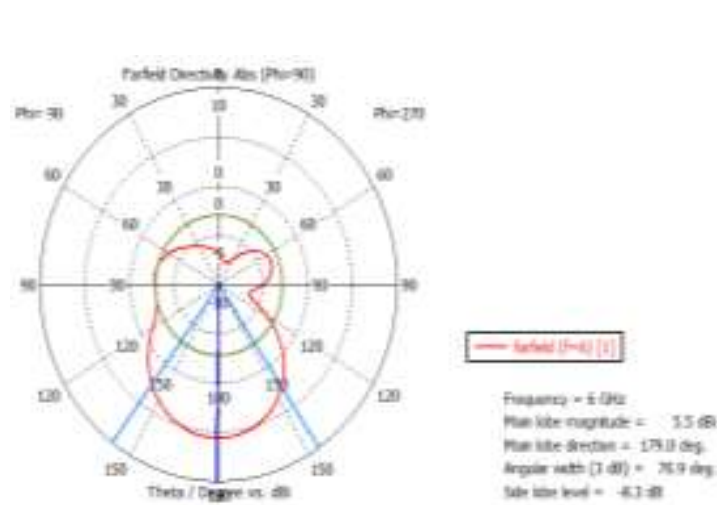

(b)

Fig. 13: a) 2D Radiation pattern for Multi-Slotted Patch Antenna. a) Design 7 and b) for Design 8 (flexible substrate)

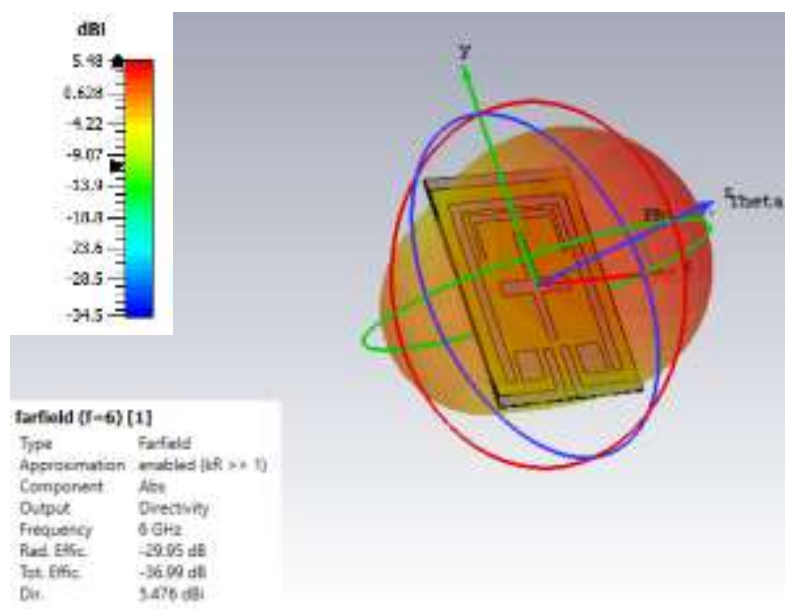

(a)

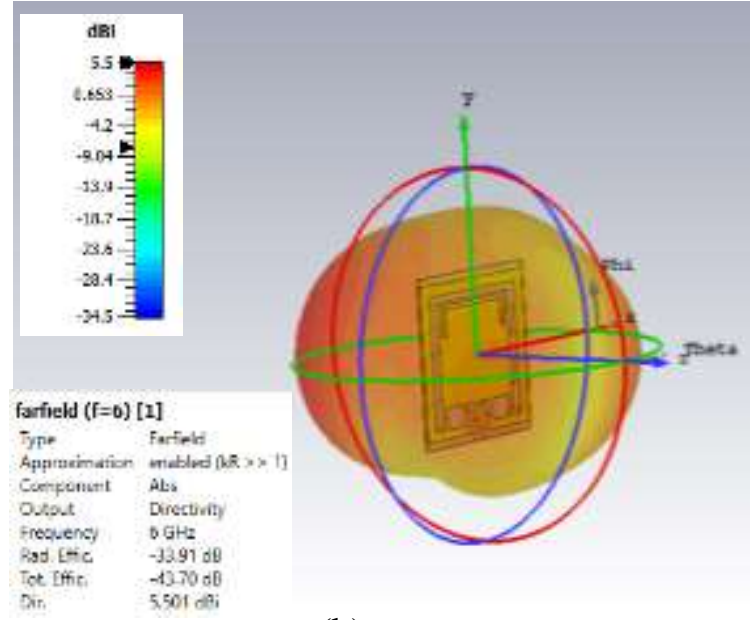

(b)

Fig. 14: a) 3D Radiation pattern for Multi Slotted Patch Antenna. a) Design 7 and b) for Design 8 (on flexible substrate)

\section{CONCLUSION :}

The work reported in this paper has five designs of simple patch, two designs of slotted and multi slotted patch antenna on flexible substrate. The slotted patch antenna design 5 has 2 bands namely: $3.25 \mathrm{GHz}$, the return loss is of $-17.47 \mathrm{~dB}$, and $5.89 \mathrm{GHz}$, the return loss is of $-21.37 \mathrm{~dB}$. Whereas, the design 6 has 4 resonant bands measured at $2.04 \mathrm{GHz}$, the $\mathrm{RL}$ is $-11.68 \mathrm{~dB}$, at $5.80 \mathrm{GHz}$, the $\mathrm{RL}$ is $-22.36 \mathrm{~dB}$, at 7.14 
$\mathrm{GHz}$, the $\mathrm{RL}$ is $-28.71 \mathrm{~dB}$ and at $8.83 \mathrm{GHz}$, the $\mathrm{Rl}$ is $-13.36 \mathrm{~dB}$. The maximum bandwidth achieved is slotted patch antenna Design 5 is 5\% and the maximum bandwidth achieved for slotted patch antenna Design 6 is $8 \%$. Whereas the design of Multi slotted patch antenna flexible substrate Design 7 and Design 8 has the maximum bandwidth achieved is $10 \%$. The multi slotted designs has also attained multiple resonance suitable for $5 \mathrm{G}$ applications with better return loss having good radiation characteristics.

\section{REFERENCES :}

[1] Banu, N., Mohamed. S., Prabhu, M. R., \& Sasikala, U. T. (2015). Design A Square Microstrip Patch Antenna for S-Band Application. IOSR Journal of Electronics and Communication Engineering, 10(2), 24-30.

Google Scholar $x^{7}$

\section{CrossRef/DOI 7}

[2] Abedin, Zain \& Ullah, Zahid. (2017). Design of a Microstrip Patch Antenna with High Bandwidth and High Gain for UWB and Different Wireless Applications. International Journal of Advanced Computer Science and Applications, 8(10), 379-382.

Google Scholar $x^{\top} \quad$ CrossRef/DOIX

[3] Akram, P \& Madhav, B. \& Sravya, G \& Sudhakar, V \& Sirisha, G \& Mounika, Ch \& Venkateswararao, M. (2017). Design and analysis of square shaped serrated patch antenna for ultra-wideband applications with single rejection band. International Journal of Engineering \& Technology, 7(1), 525-529.

Google Scholar X

\section{CrossRef/DOIX}

[4] Tarpara, N. M., Rathwa, R. R., \& Kotak, N. A. (2018). Design of slotted microstrip patch antenna for 5G application. Int. Res. J. Eng. Technol, 5(4), 2827-2832.

Google Scholar $x^{7} \quad$ CrossRef/DOIX

[5] Madhan, M. D., Subitha, D. (2019). Millimeter-wave Microstrip patch antenna designed of 5G. International Journal of Innovative Technology and Exploring Engineering, 8(12), 1183-1187. Google Scholar $x^{7} \quad$ CrossRef/DOI $x^{7}$

[6] Muhammad Afiq Abdul Aziz, Norhudah Seman, Tien Han Chua (2019). Microstrip antenna design with partial ground at frequencies above $20 \mathrm{GHz}$ for $5 \mathrm{G}$ telecommunication systems. Indonesian Journal of Electrical Engineering and Computer Science, 15(3), 1466-1473. Google Scholar $X^{7} \quad$ CrossRef/DOIX

[7] Naser Ojaroudi Parchin, Yasir I. A. Al-Yasir, Haleh Jahanbakhsh Basherlou, and Raed A. AbdAlhameed (2020). A Closely Spaced Dual-Band MIMO Patch Antenna with Reduced Mutual Coupling for 4G/5G Applications. Progress In Electromagnetics Research C, 101(1), 71-80.

Google Scholar ${ }^{7} \quad$ CrossRef/DOI $X^{\top}$

[8] Azim, Rezaul \& Meaze, AKM Moinul \& Affandi, Adnan \& Alam, Md Mottahir \& Aktar, Rumi \& Mia, Md \& Alam, Touhidul \& Samsuzzaman, Md \& Islam, Mohammad. (2021). A multi-slotted antenna for LTE/5G Sub-6 GHz wireless communication applications. International Journal of Microwave and Wireless Technologies, 13(5), 486-496.

Google Scholar $X^{7} \quad$ CrossRef/DOI 7

[9] Zoukalne, K., Chaibo, A., \& Khayal, M. Y. (2020). Design of Microstrip Patch Antenna Array for 5G Resonate at 3.6GHz. Current Journal of Applied Science and Technology, 39(34), 164-170. Google Scholar $x^{7}$ CrossRef/DOIX

[10] Mahfuz, M.M. \& Islam, Md \& Habaebi, Mohamed \& Sakib, Nazmus \& Abdul Malek, Norun \& Hossain, A.K.M Zakir. (2021). Design of UWB Patch Antenna with 5G Lower Band Notch Characteristics Using Ring Shape Resonator. 2021 8th International Conference on Computer and Communication Engineering (ICCCE), IEEE Xplore.

Google Scholar $X^{\top} \quad$ CrossRef/DOIX

[11] Mohammad Alibakhshikenari, Sadegh Mansouri Moghaddam, Ashraf Uz Zaman, Jian Yang, Bal Singh Virdee and Ernesto Limiti (2019). Wideband Sub-6 GHz Self-Grounded Bow-Tie Antenna 
with New Feeding Mechanism for 5G Communication Systems. In 2019 13th European Conference on Antennas and Propagation (EuCAP) (pp. 1-4). IEEE.

Google Scholar X CrossRef/DOIX

[12] Balanis, C. A. (2005). Antenna theory: Analysis and design.3rd ed, John Wiley publishing house. https://www.academia.edu/19892973/Antenna Theory Analysis and Design 3rd Edition. Retrieved on 20/10/2021. 